\title{
Editorial
}

Digestion

\section{The Fructose Hydrogen Breath Test: Nothing Behind the Sweet Fog?}

\author{
Benjamin Misselwitz $^{\mathrm{a}}$ Mark Fox $^{\mathrm{b}}$ \\ ${ }^{a}$ Division of Gastroenterology and Hepatology, University Hospital Zurich, University of Zurich, Zurich, Switzerland; \\ ${ }^{\mathrm{b}}$ Abdominal Center: Gastroenterology, St. Claraspital, Basel, Switzerland
}

Fructose consumption has steadily increased in Western countries, with adolescents consuming up to $70 \mathrm{~g}$ of fructose per day [1]. Apples, pears or grapes contain $\sim 8 \mathrm{~g}$ fructose per $100 \mathrm{~g}$; however, most fructose intake is derived from processed sugars in many contemporary foods and sweetened beverages. Fructose is 1.5-2.5 times sweeter than glucose; however, it fails to activate normal satiety signals, increasing caloric intake and weight gain. Specific metabolic properties of fructose further contribute to metabolic syndrome, and fructose consumption has now become a public health concern [2].

Digestive discomfort after fructose intake also impacts the health. Food intolerance disorders affect approximately $20 \%$ of the general population [3] and $70 \%$ of individuals with functional gastrointestinal disorders (FGID) [4]. Fructose is frequently blamed as a cause for symptoms such as diarrhea, pain, and bloating.

Fructose absorption is mediated by the passive glucose transporter GLUT5 and the active glucose transporter GLUT2; however, small intestinal fructose resorption capacity is limited [5]. Non-resorbed fructose will be metabolized by the colonic microbiota, leading to the production of $\mathrm{CO}_{2}, \mathrm{H}_{2}, \mathrm{CH}_{4}$, short-chain fatty acid, and possibly intestinal symptoms. The fructose $\mathrm{H}_{2}$ breath test (FHBT) aims to identify individuals with (i) fructose

\section{KARGER}

(c) 2018 S. Karger AG, Basel

E-Mail karger@karger.com

www.karger.com/dig "malabsorption," assessed by high $\mathrm{H}_{2}$ values in expiratory air and (ii) symptoms after oral fructose challenge ("intolerance"). To date, the clinical impact of FHBT remains unclear.

A paper in this issue of Digestion addresses this question (Helwig et al. [6], Digestion, 2018). The authors analyze 562 consecutive $50 \mathrm{~g}$ FHBT. As expected for a high-dose fructose challenge [7], FHBT showed fructose malabsorption in a large proportion of individuals (66.5\%). $\mathrm{H}_{2}$-levels correlated with symptoms during the test, confirming that breakdown products of poorly absorbed fermentable oligo-, di-, and mono-saccharides and polyols (FODMAPs) contribute to the occurrence and severity of symptoms [8].

The most interesting part of this work was the impact of professional dietary advice to 246 patients with a positive FHBT with symptoms. Patients completed a 10-day "open-label" fructose-free diet. Almost half (47\%) the patients responded completely and $45 \%$ partially to this intervention. However, neither the $\mathrm{H}_{2}$ response nor the symptoms during testing significantly predicted this dietary response.

This is, to our knowledge, the largest study addressing the clinical utility of FHBT $[9,10]$. The negative outcome cautions against non-critical interpretation of FHBT. In- 
deed, based on this data, the clinical utility FHBT seems to be so limited that this test might have no role in clinical practice.

This study has several limitations: (i) Neither patients nor therapists were blinded to FHBT results, and strong placebo effects regarding dietary interventions were known in FGID patients. (ii) Lack of a control group (or control diet). (iii) Fructose exclusion might also exclude other compounds responsible for food intolerance. (iv) Fructose-free diet was not offered to patients with negative FHBT. Therefore, the negative predictive value of FHBT remains unknown. (v) No long-term outcome data ( $>10$ days) are provided.

One also wonders whether results of this trial would have been different with a lower fructose dosage. Fifty grams fructose (corresponding to $800 \mathrm{~mL}$ of a sweetened beverage or $600 \mathrm{~g}$ apples) might not cause symptoms when taken with normal food since uptake of fructose is facilitated in the presence of glucose and with food. Conversely, high amounts of pure fructose might exceed fructose absorption capacity in most humans and a smaller dose would likely reduce false positive results.

The negative results of the Helwig study are in line with data demonstrating a similar expression of GLUT2, GLUT5 mRNA and protein in small bowel biopsies in 11 individuals with intolerance symptoms and positive FHBT and 15 control individuals without fructose intolerance and normal FHBT [11]. Another study demonstrated reduced GLUT5 expression in inflammation [12], reminiscent to induction of lactose malabsorption by chronic viral infections [13]. Further, fructose treatment increased GLUT5 expression in the murine gut 5 times [5], suggesting that fructose exposure before FHBT might strongly influence the results.

For most FGID, the burden of symptoms is determined not only by altered motility or digestion, but also by visceral sensitivity to gastrointestinal events. For instance, $20 \mathrm{~g}$ lactose hydrogen breath test is three times more likely to produce symptoms in patients with irritable bowel syndrome (IBS) than in healthy controls [14]. Moreover, a recent study showed that colon hypersensitivity to gas distension, more than gas production itself, produces symptoms in IBS patients [15].

Further, considering the complexity of our nutrition, fructose will rarely be the only offender. Rather than focusing on individual carbohydrates, the FODMAP hypothesis suggests that a wide range of poorly absorbed carbohydrates can cause functional gastrointestinal symptoms [8]. The low-FODMAP diet will simultaneously reduce all offenders, relieving symptoms in approximately $70 \%$ of IBS patients [8].

Looking ahead, the ideal clinical investigation would predict the response to a well-validated dietary intervention. Symptoms after a lactulose challenge (an indigestible FODMAP producing an $\mathrm{H}_{2}$-response in most patients) [16] might confirm FODMAPs as a trigger for symptoms of a given patient. Blinded testing of various FODMAPs could also help guiding a rational exclusion of compounds. The goal of testing should be to identify patients benefiting from a diet and compounds to be excluded.

Finally, the report by Helwig et al. [6] showed that diet relieved symptoms at least partially in $92 \%$ of patients. Therefore, for patients with FGID, showing interest in patient's symptoms, investigating the respective pathogenesis as well as providing a clear disease concept and a therapeutic plan can benefit many patients.

\section{Disclosure Statement}

The authors declare no conflict of interest.

\section{References}

1 Vos MB, Kimmons JE, Gillespie C, Welsh J, Blanck HM: Dietary fructose consumption among US children and adults: the Third National Health and Nutrition Examination Survey. Medscape J Med 2008;10: 160.

2 Lustig RH: Fructose: it's "alcohol without the buzz." Adv Nutr 2013;4:226-235.

3 Lomer MC: Review article: the aetiology, diagnosis, mechanisms and clinical evidence for food intolerance. Aliment Pharmacol Ther 2015;41:262-275.
4 Monsbakken KW, Vandvik PO, Farup PG: Perceived food intolerance in subjects with irritable bowel syndrome - etiology, prevalence and consequences. Eur J Clin Nutr 2006;60: 667-672.

5 Patel C, Douard V, Yu S, Gao N, Ferraris RP: Transport, metabolism, and endosomal trafficking-dependent regulation of intestinal fructose absorption. FASEB J 2015;29:40464058 .

6 Helwig U, Koch AK, Koppka N, Holtmann $S$, Langhorst J: The predictive value of the hy- drogen breath test in the diagnosis of fructose malabsorption. Digestion 2019, DOI: 101159/0000489877.

7 Rao SS, Attaluri A, Anderson L, Stumbo P: Ability of the normal human small intestine to absorb fructose: evaluation by breath testing. Clin Gastroenterol Hepatol 2007;5:959-963.

8 Tuck CJ, Muir JG, Barrett JS, Gibson PR: Fermentable oligosaccharides, disaccharides, monosaccharides and polyols: role in irritable bowel syndrome. Expert Rev Gastroenterol Hepatol 2014;8:819-834. 
9 Choi YK,:. Fructose intolerance in IBS and utility of fructose-restricted diet. J Clin Gastroenterol 2008;42:233-238.

10 Corlew-Roath M, Di Palma JA: Clinical impact of identifying lactose maldigestion or fructose malabsorption in irritable bowel syndrome or other conditions. South Med J 2009; 102:1010-102.

11 Wilder-Smith CH, Li X, Ho SS, Leong SM, Wong RK, Koay ES, et al: Fructose transporters GLUT5 and GLUT2 expression in adult patients with fructose intolerance. United European Gastroenterol J 2014;2:14-21.

12 Rodriguez-Yoldi MJ, Gascon S, Barranquero C, Garcia-Barrios A, Osada J: Involve- ment of intracellular signaling in the IL-1beta inhibitory effect on fructose intestinal absorption. J Cell Physiol 2015;230:896902.

13 Bonani M, Pereira RM, Misselwitz B, Fehr T, Wuthrich RP, Franzen D: Chronic norovirus infection as a risk factor for secondary lactose maldigestion in renal transplant recipients: a prospective parallel cohort pilot study. Transplantation 2017;101:14551460.

14 Yang J, Deng Y, Chu H, Cong Y, Zhao J, Pohl $\mathrm{D}$, et al: Prevalence and presentation of lactose intolerance and effects on dairy product intake in healthy subjects and patients with irritable bowel syndrome. Clin Gastroenterol Hepatol 2013;11:262-268.e1.

15 Major G, Pritchard S, Murray K, Alappadan JP, Hoad CL, Marciani L, et al: Colon hypersensitivity distension, rather than excessive gas production, produces carbohydrate-related symptoms in individuals with irritable bowel syndrome. Gastroenterology 2017;152: 124-133.

16 Le Neve B, Posserud I, Bohn L, Guyonnet D, Rondeau P, Tillisch K, et al: A combined nutrient and lactulose challenge test allows symptom-based clustering of patients with irritable bowel syndrome. Am J Gastroenterol 2013;108:786-795. 